\title{
Nye diagnosekriterier for insomni og sammenhengen mellom insomni, angst og depresjon
}

ORIGINALARTIKKEL

\section{INGER SOFIE OLUFSEN}

E-post: inger.olufsen@student.uib.no

Institutt for global helse og samfunnsmedisin

Universitetet i Bergen

Hun har bidratt med idé, planlegging og utforming av prosjektet samt utforming, revisjon og endelig godkjenning av manuskriptet.

Inger Sofie Olufsen er medisinstudent.

Forfatteren har fylt ut ICMJE-skjemaet og oppgir ingen interessekonflikter.

\section{MARIE E. SØRENSEN}

Institutt for global helse og samfunnsmedisin

Universitetet i Bergen

Hun har bidratt med idé, planlegging og utforming av prosjektet samt utforming, revisjon og endelig godkjenning av manuskriptet.

Marie E. Sørensen er medisinstudent.

Forfatteren har fylt ut ICMJE-skjemaet og oppgir ingen interessekonflikter.

\section{BJØRN BJORVATN}

Institutt for global helse og samfunnsmedisin

Universitetet i Bergen

og

Nasjonal kompetansetjeneste for søvnsykdommer

Haukeland universitetssjukehus

Han har bidratt med idé, planlegging og utforming av prosjektet samt utforming, revisjon og endelig godkjenning av manuskriptet.

Bjørn Bjorvatn er spesialist i allmennmedisin, professor, søvnspesialist ved Bergen søvnsenter og leder for Nasjonal kompetansetjeneste for søvnsykdommer.

Forfatteren har fylt ut ICMJE-skjemaet og oppgir følgende interessekonflikter: Han har mottatt foredragshonorar fra ResMed og Philips og godtgjørelse fra Fagbokforlaget og Gyldendal Akademisk for bøker om søvn og søvnlidelser.

\section{BAKGRUNN}

I klassifikasjonssystemet Diagnostic Statistical Manual of Mental Disorders, versjon 5 (DSM-5) er diagnosekriteriene for insomni endret. De samme endringene ventes i International Classification of Diseases, versjon 11 (ICD-11). I denne studien ser vi på hvilken effekt endringene i diagnosekriteriene for insomni har på sammenhengen mellom insomni, angst og depresjon. 
Studien er basert på en spørreundersøkelse med 68 spørsmål som ligger på hjemmesiden til Nasjonal kompetansetjeneste for søvnsykdommer. Undersøkelsen åpnet i 2012, våre data ble hentet ut i 2016. Undersøkelsen inkluderte validerte spørreskjema for insomni, angst og depresjon: Bergen insomniskala og Hospital Anxiety and Depression Scale (HADS).

\section{RESULTATER}

48932 deltakere fylte kriteriene for insomni basert på DSM-IV. Av disse fylte 42873 (87,6\%) kriteriene for insomni også i DSM-5, de resterende 6059 (12,4\%) fylte ikke de nye kriteriene. Blant deltakere som fylte kriteriene for insomni i henhold til DSM-IV, var det 46704 som også svarte på spørsmålene om angst og depresjon. Forekomsten av mulig angst (HADS-A $\geq$ 8) blant dem som fylte de nye kriteriene var 25708 (62,9\%), mens forekomsten av mulig depresjon (HADS-D $\geq 8$ ) var 15591 (38,1\%). Blant deltakere som ikke fylte de nye kriteriene, var forekomsten signifikant lavere: mulig angst 2791 (48,1\%) og mulig depresjon 1763 $(30,4 \%)$ (begge $\mathrm{p}<0,001)$.

\section{FORTOLKNING}

Studien indikerer at de nye diagnosekriteriene for insomni forsterket sammenhengen mellom insomni, angst og depresjon. Dette betyr trolig at flere pasienter med insomni vil ha komorbid psykisk lidelse med de nye diagnosekriteriene.

I perioden 1999/2000-2009/10 økte forekomsten av insomni i Norge fra 11,9\% til 15,5\% (1). En studie publisert i 2018 viste en forekomst på 20 \% (2). Insomni gir økt risiko for å utvikle psykiske lidelser (3-5). Det er vist at forekomsten av klinisk signifikant angst og depresjon er 10-17 ganger høyere blant personer med insomni sammenliknet med personer uten insomni (4). Samtidig er det vist at forekomsten av insomni er betydelig høyere blant pasienter med angst og depresjon enn i normalbefolkningen (6). Nyere forskning peker på at sammenhengen går begge veier $(7,8)$.

I 2013 kom den femte versjonen av klassifikasjonssystemet DSM (Diagnostic Statistical Manual of Mental Disorders), hvor diagnosekriteriene for insomni er endret. En av de store endringene var å fjerne ikke-restituerende søvn (dårlig søvnkvalitet) som et symptom på insomni. Dette ble gjort for tydeligere å skille insomni fra andre søvnlidelser, som f.eks. obstruktiv søvnapné, hvor ikke-restituerende søvn er et vanlig symptom. For å få diagnosen insomni i DSM-5 kreves dermed vansker med initiering eller opprettholdelse av søvn i tillegg til nedsatt dagtidsfunksjon eller klinisk signifikant ubehag grunnet søvnproblemene. I DSM-IV derimot var det krav om at pasienten enten hadde vansker med initiering, opprettholdelse av søvn eller problemer med ikke-restituerende søvn i tillegg til nedsatt dagtidsfunksjon.

I 2018 kom første utkast til ICD-11 (International Classification of Diseases, 11th Revision) (9). Som i DSM-5 har man her fjernet ikke-restituerende søvn fra diagnosekriteriene for insomni. Den endelige versjonen ble godkjent i 2019, og skal etter hvert innføres i Norge.

Hensikten med denne artikkelen var å undersøke hvilken effekt endringen i diagnosekriteriene for insomni har på forekomsten av insomni og på sammenhengen mellom insomni, angst og depresjon.

\section{Materiale og metode}

En nettbasert spørreunders $\varnothing$ kelse for personer som oppga å ha et søvnproblem, startet $\mathrm{i}$ februar 2012 etter å ha vært annonsert i Dagbladet og på TV2. Den har siden vært tilgjengelig på hjemmesiden til Nasjonal kompetansetjeneste for søvnsykdommer (www.sovno.no). Deltakerne besvarte validerte spørreskjema om insomni, angst og depresjon. 
Vi hentet ut våre data i juni 2016 og totalt 77786 personer hadde svart på hele eller deler av undersøkelsen. 53540 deltakere hadde svart på spørsmålene om insomni, og 50942 hadde svart på spørsmålene om angst og depresjon.

Ingen personidentifiserbare data ble samlet inn. Regional komité for medisinsk og helsefaglig forskningsetikk (REK) anså dette som kvalitetssikring og ikke et forskningsprosjekt. Det var derfor ikke nødvendig å søke dem om etisk godkjenning.

\section{MÅLEREDSKAP}

Diagnosen insomni ble satt ved bruk av Bergen insomniskala (BIS). Skalaen ble utviklet og validert basert på DSM-IV-kriteriene for insomni og består av seks spørsmål (10). De første tre handler om innsovningsvansker, oppvåkning under søvn og tidlig morgenoppvåkning, spørsmål 4 om pasienten føler seg uthvilt etter søvn, og spørsmål 5 og 6 handler om dagtidsfungering og misnøye med søvnen. Hvert spørsmål graderes på en skala o-7 etter hvor mange dager i uka pasienten har opplevd dette siste måned (10).

En skår på $\geq 3$ på ett eller flere av de fire første spørsmålene, kombinert med en skår på $\geq 3$ på ett eller begge av de to siste spørsmålene fyller kriteriene for insomni i henhold til DSM-IV (10). Da ikke-restituerende søvn er fjernet fra diagnosekriteriene i DSM-5, vil ikke spørsmål 4 om uthvilthet etter søvn lenger ha noen innvirkning på insomnidiagnosen. Dermed vil en skår på $\geq 3$ på ett eller flere av de tre første spørsmålene kombinert med en skår på $\geq 3$ på ett eller begge spørsmål 5 og 6 fylle kriteriene i henhold til DSM-5.

Denne studien tok utgangspunkt i deltakere som fylte diagnosekriteriene for insomni i henhold til DSM-IV $(\mathrm{N}=48$ 932). Disse ble delt inn i to grupper hvor den ene gruppen fylte kriteriene i henhold til DSM-5 $(n=42873)$, mens den andre gruppen ikke fylte de nye kriteriene ( $n=6$ 059). Sistnevnte gruppe hadde altså ikke problemer med initiering eller opprettholdelse av søvn, men fylte gamle diagnosekriterier fordi de hadde problemer med ikke-restituerende søvn (IRS-insomni).

Angst og depresjon ble diagnostisert ved bruk av en validert norsk versjon av Hospital Anxiety and Depression Scale (HADS). Dette skjemaet består av 14 spørsmål, der halvparten måler symptomer på angst og halvparten måler symptomer på depresjon. Hvert spørsmål får en skår o-3, som indikerer grad av symptom den siste uken. I tråd med tidligere studier ble en totalskår på $\geq 8$ innenfor én av de to spørsmålskategoriene angst og depresjon brukt som grense for mulig diagnose (11).

\section{STATISTIKK}

Khikvadrattest ble brukt for å sammenlikne forekomst av mulig angst og depresjon (HADS $\geq 8$ ) mellom deltakere med DSM-5-insomni og deltakere med insomni med ikkerestituerende søvn. Signifikansverdien ble satt til $\mathrm{p}<0,05$. Alle analyser ble gjort ved hjelp av SPSS versjon 25 .

\section{Resultater}

Gjennomsnittsalderen på deltakerne var 35,1 år (standardavvik 13,5 år), median 33 år. Flere kvinner (6o,4\%) enn menn (39,6\%) deltok. 48,9\% hadde gått på høyskole eller universitet og $68,4 \%$ av deltakerne bodde i bykommune.

53540 (68,8\%) av deltakerne svarte på spørsmålene om insomni. Av disse oppfylte 48932 (91\%) DSM-IV-kriteriene. 50942 (65,5\%) svarte på spørsmålene om angst og depresjon. Av disse hadde 29960 (58,8\%) mulig angst, mens 18017 (35,4\%) hadde mulig depresjon (tabell 1).

\section{Tabell 1}


Fordeling av demografiske data blant 77786 personer med søvnproblemer som deltok i en nettbasert spørreundersøkelse på hjemmesiden til Nasjonal kompetansetjeneste for søvnsykdommer i perioden 2012-16.

\begin{tabular}{|c|c|}
\hline Variabel & Antall (\%) \\
\hline \multicolumn{2}{|l|}{ Kjønn } \\
\hline Kvinne & $47012(60,4)$ \\
\hline Mann & $30774(39,6)$ \\
\hline \multicolumn{2}{|l|}{ Alder (år) } \\
\hline $15-24$ år & $20652(26,5)$ \\
\hline $25-34$ år & $21032(27,0)$ \\
\hline $35-44$ år & $16942(21,8)$ \\
\hline 45-54 år & $11268(14,5)$ \\
\hline 55-64 år & $5851(7,5)$ \\
\hline $65+$ & $1995(2,6)$ \\
\hline Mangler data & $46(0,1)$ \\
\hline \multicolumn{2}{|l|}{ Bosetting } \\
\hline By & $53210(68,4)$ \\
\hline Landlig område & $24149(31,0)$ \\
\hline Mangler data & $427(0,5)$ \\
\hline \multicolumn{2}{|l|}{ Sivilstatus } \\
\hline Gift & $22601(29,1)$ \\
\hline Ugift & $28905(37,2)$ \\
\hline Samboer & $21047(27,1)$ \\
\hline Skilt & $3173(4,1)$ \\
\hline Separert & $940(1,2)$ \\
\hline Enke/enkemann & $1044(1,3)$ \\
\hline Mangler data & $76(0,1)$ \\
\hline \multicolumn{2}{|l|}{ Utdanning } \\
\hline Grunnskole & $9077(11,7)$ \\
\hline Videregående skole & $10375(13,3)$ \\
\hline Yrkesskole/fagskole & $20214(26,0)$ \\
\hline Universitet/ høyskole & $38058(48,9)$ \\
\hline Mangler data & $62(0,1)$ \\
\hline \multicolumn{2}{|l|}{ Insomni } \\
\hline I henhold til DSM-IV' & $48932(62,9)$ \\
\hline I henhold til DSM- $5^{1}$ & $42873(55,1)$ \\
\hline IRS-insomni $^{2}$ & $6059(7,8)$ \\
\hline Ikke insomni & $4608(5,9)$ \\
\hline Mangler data & $24246(31,2)$ \\
\hline \multicolumn{2}{|l|}{ Angst/depresjon } \\
\hline Mulig angst og/eller depresjon & $33119(42,6)$ \\
\hline Mulig angst $\left(\mathrm{HADS}-\mathrm{A}^{3} \geq 8\right)$ & $29960(38,5)$ \\
\hline Mulig depresjon (HADS- $\left.D^{4} \geq 8\right)$ & $18017(23,2)$ \\
\hline Ikke angst eller depresjon & $17823(22,9)$ \\
\hline Mangler data & $26844(34,5)$ \\
\hline
\end{tabular}

${ }^{1}$ DSM-IV og DSM-5 = Diagnostic and Statistical Manual of Mental Disorders 4. utg. og 5. utg.

${ }^{2}$ IRS-insomni = insomni med ikke-restituerende søvn. Deltakere som har svart at de føler seg lite uthvilt etter søvn, men ikke har problemer med initiering og/eller opprettholdelse av søvn, dvs. de fyller diagnosekriteriene for insomni i henhold til DSM-IV, men ikke i henhold til DSM-5

${ }^{3}$ HADS-A = Hospital Anxiety and Depression Scale - anxiety

${ }^{4}$ HADS-D = Hospital Anxiety and Depression Scale - depression 
Av de 48932 deltakerne som fylte diagnosekriteriene for insomni ved bruk av DSM-IV, var det $42873(87,6 \%)$ som også innfridde kriteriene basert på DSM-5. De resterende 6059 $(12,4 \%)$ oppga problemer med ikke-restituerende søvn og fylte ikke de nye diagnosekriteriene.

46704 av deltakerne som fylte kriteriene for insomni etter DSM-IV, besvarte også spørsmålene om angst og depresjon (HADS). Det var signifikant høyere forekomst av mulig angst blant deltakerne med DSM-5-insomni sammenliknet med deltakere med insomni med ikke-restituerende søvn. Av deltakere med DSM-5-insomni hadde $62,9 \%$ mulig angst, sammenliknet med 48,1\% av deltakere med insomni med ikke-restituerende søvn ( $\mathrm{p}<$ o,oo1). Av deltakerne med DSM-5-insomni hadde 38,1\% mulig depresjon, sammenliknet med 30,4\% av deltakere med ikke-restituerende $s ø v n(p<0,001)$ (tabell 2$)$.

\section{Tabell 2}

Nettbasert spørreundersøkelse blant deltakere med søvnproblemer i tidsperioden 2012-16. Forskjeller i forekomst av angst og depresjon blant deltakere med insomni med ikkerestituerende søvn og deltakere med insomni i henhold til DSM-5. Prosentene er beregnet ut ifra antall deltakere med mulig insomni som også svarte på spørsmålene om angst og depresjon.

\begin{tabular}{|c|c|c|c|}
\hline & \multicolumn{3}{|c|}{$\begin{array}{l}\text { IRS-insomni }^{1}\left(n=5 \text { 806) DSM- } 5^{2} \text {-insomni }(n=40098) \text { P-verdi }\right. \\
\begin{array}{ll}\text { Antall }(\%) & \text { Antall }(\%)\end{array}\end{array}$} \\
\hline $\begin{array}{l}\text { Mulig angst } \\
\left(\text { HADS- } A^{3} \geq 8\right)\end{array}$ & $2791(48,1)$ & $25708(62,9)$ & $<0,001$ \\
\hline $\begin{array}{l}\text { Mulig depresjon } \\
\left(\text { HADS- } D^{4} \geq 8\right)\end{array}$ & $1763(30,4)$ & $15591(38,1)$ & $<0,001$ \\
\hline
\end{tabular}

${ }^{1}$ IRS-insomni = insomni med ikke-restituerende søvn. Deltakere som har svart at de føler seg lite uthvilt etter søvn, men ikke har problemer med initiering og/eller opprettholdelse av søvn, dvs. de fyller diagnosekriteriene for insomni i henhold til DSM-IV, men ikke i henhold til DSM-5

${ }^{2}$ DSM-5 = Diagnostic and Statistical Manual of Mental Disorders, 5.utg.

${ }^{3}$ HADS-A $=$ Hospital Anxiety and Depression Scale - anxiety

${ }^{4}$ HADS-D = Hospital Anxiety and Depression Scale - depression

\section{Diskusjon}

Studien viste en betydelig reduksjon i forekomst av mulig insomni ved fjerning av ikkerestituerende søvn som diagnosekriterium. Det var altså en betydelig andel deltakere som tidligere hadde fått insomnidiagnosen basert på ikke-restituerende søvn uten å ha problemer med initiering eller opprettholdelse av søvnen. At bruk av nye kriterier for insomni gir en stor reduksjon i forekomsten, er også tidligere vist i en studie gjort på en normalbefolkning (12).

Et av argumentene bak endringen i diagnosekriteriene er at personer med ikkerestituerende søvn mer sannsynlig lider av andre søvnlidelser enn insomni, som for eksempel obstruktiv søvnapné. Etter insomni er søvnapné den vanligste søvnsykdommen (13). Ett av hovedsymptomene på søvnapné er økt tretthet på dagtid på grunn av dårlig søvnkvalitet. Det kan tenkes at personer med ikke-restituerende søvn ikke har insomni i vanlig forstand, men søvnapné eller andre søvnsykdommer som gjør at de føler seg for lite utvilt etter søvn. Fjerning av ikke-restituerende søvn fra diagnosekriteriene for insomni vil på den måten ekskludere personer som kan ha fått diagnosen på feil grunnlag, og dermed rendyrke diagnosen insomni. Insomni og søvnapné har forskjellig behandling, og en mer riktig diagnosesetting vil dermed ha betydning for valg og nytte av behandling. 
Vår studie viste høy forekomst av mulig angst og depresjon blant deltakere med insomni basert på DSM-5. Studien HUNT-3 (Helseundersøkelsen i Nord-Trøndelag) har til sammenlikning vist en forekomst av mulig angst på 34,6\% og mulig depresjon på 29,8\% blant deltakere med insomni (7). HUNT-3 brukte også HADS-skår for å stille diagnosene angst og depresjon, slik vi gjorde i vår studie. Derimot ble det ikke brukt et validert spørreskjema for å diagnostisere insomni. En mulig forklaring på forskjellen i forekomst kan dermed være bruk av forskjellige kriterier for å stille diagnosen. En annen mulig forklaring er at utvalget i HUNT-3 var tilfeldig og ikke personer som i utgangspunktet rapporterte om søvnproblemer. Til slutt må det påpekes at HUNT-3 ble utført i 2006-o8, og siden da har forekomsten av insomni $\varnothing \mathrm{kt}$ i den generelle befolkningen $(1,2)$.

Studien viste betydelig høyere forekomst av mulig angst og depresjon blant deltakere som fylte kriterier for insomni i henhold til DSM-5 enn blant dem som ikke fylte de nye kriteriene. Tidligere studier har vist en tydelig sammenheng mellom insomni, angst og depresjon (4, 7, 8). Våre funn indikerer at denne sammenhengen blir forsterket i de nye diagnosekriteriene. Det er ikke vist like stor sammenheng mellom søvnapné, angst og depresjon (14) som mellom insomni, angst og depresjon (4, 7, 8). En mer riktig diagnostisering av personer med insomni kan dermed forklare at sammenhengen mellom insomni, angst og depresjon forsterkes ved bruk av nye diagnosekriterier. Vi anbefaler videre forskning på forekomst av andre søvnlidelser blant personer med ikke-restituerende søvn.

Ved innføring av nye diagnosekriterier vil trolig en større andel av pasientene med insomni ha komorbid psykisk lidelse. Det vil dermed være viktig å fortsette å fokusere på diagnostisering og behandling av komorbid psykisk lidelse hos pasienter med insomni.

\section{STYRKER OG BEGRENSNINGER}

En stor styrke ved studien var at den hadde svært mange deltakere. Det gjør det lettere å påvise statistiske forskjeller. Faren er imidlertid at forskjellene ikke nødvendigvis er klinisk relevante. En begrensning ved studien var at mange deltakere ikke besvarte spørsmålene om insomni, angst og depresjon. Det er viktig å understreke at datamaterialet er selektert. Mange deltakere ble rekruttert via omtale i Dagbladet eller på TV2.no. I tillegg måtte deltakerne rapportere at de hadde et søvnproblem for å delta i undersøkelsen.

Undersøkelsen sier dermed ikke noe om den reelle forekomsten av insomni, angst og depresjon i befolkningen. En annen svakhet ved denne type undersøkelse er at diagnostisering ikke skjer ved direkte pasientkontakt. Man går dermed glipp av viktig klinisk informasjon som kan påvirke diagnosesettingen. I tillegg vil det være større usikkerhet knyttet til om deltakeren har forstått spørsmålet riktig. For å kunne stille sikker diagnose kreves et klinisk intervju.

En styrke ved studien var at det ble brukt validerte spørreskjema for insomni, angst og depresjon. Spørreskjemaene (Bergen insomniskala og HADS) har vært mye brukt innen søvnforskning og i store studier på angst og depresjon. En svakhet med Bergen insomniskala er at denne er validert basert på DSM-IV-kriterier og ikke DSM-5. En svakhet ved HADS-skjemaet er at spørsmålene er begrenset til å dekke ikke-vegetative symptomer på angst og depresjon, noe som betyr at symptomer som tretthet, utmattelse, søvnproblemer og hodepine ikke inngår i skjemaet (11).

\section{Konklusjon}

Studien viste at å fjerne ikke-restituerende søvn som et symptom på insomni fra diagnosekriteriene forsterker sammenhengen mellom mulig insomni og mulig angst og depresjon. Forekomsten av mulig angst og depresjon var høyere blant deltakere som fylte nye kriterier for insomni enn blant dem som ikke fylte nye kriterier. 


\section{HOVEDFUNN}

Blant deltakere som innfridde gamle insomnikriterier var det 12,4\% som ikke innfridde de nye kriteriene.

Forekomsten av mulig angst var hhv. 62,9\% og 48,1\% blant deltakere som innfridde versus ikke innfridde de nye diagnosekriteriene for insomni.

Forekomsten av mulig depresjon var hhv. 38,1\% og 30,4\% blant deltakere som innfridde versus ikke innfridde de nye diagnosekriteriene for insomni.

\section{LITTERATUR:}

1. Pallesen S, Sivertsen B, Nordhus IH et al. A 10-year trend of insomnia prevalence in the adult Norwegian population. Sleep Med 2014; 15: 173-9. [PubMed][CrossRef]

2. Bjorvatn B, Waage S, Pallesen S. The association between insomnia and bedroom habits and bedroom characteristics: an exploratory cross-sectional study of a representative sample of adults. Sleep Health 2018; 4: 188-93. [PubMed][CrossRef]

3. Ohayon MM, Roth T. Place of chronic insomnia in the course of depressive and anxiety disorders. J Psychiatr Res 2003; 37: 9-15. [PubMed][CrossRef]

4. Taylor DJ, Lichstein KL, Durrence HH et al. Epidemiology of insomnia, depression, and anxiety. Sleep 2005; 28: 1457-64. [PubMed][CrossRef]

5. Taylor DJ, Lichstein KL, Durrence HH. Insomnia as a health risk factor. Behav Sleep Med 2003; 1: 227-47. [PubMed][CrossRef]

6. Seow LSE, Verma SK, Mok YM et al. Evaluating DSM-5 insomnia disorder and the treatment of sleep problems in a psychiatric population. J Clin Sleep Med 2018; 14: 237-44. [PubMed][CrossRef]

7. Sivertsen B, Salo P, Mykletun A et al. The bidirectional association between depression and insomnia: the HUNT study. Psychosom Med 2012; 74: 758-65. [PubMed][CrossRef]

8. Jansson-Fröjmark M, Lindblom K. A bidirectional relationship between anxiety and depression, and insomnia? A prospective study in the general population. J Psychosom Res 20o8; 64: 443-9.

[PubMed][CrossRef]

9. ICD-11 for Mortality and Morbidity statistics. Geneva: World Health Organization, 2018. https://icd.who.int/browse11/lm/en?fbclidIwAR1XX3joehDaNxo6Rgs_Xyy4L5ZUptkdlTX6PWSz76O2cEGawylN1fjQefY\#/http://id.who.int/icd/enti ty/323148092 Lest 15.12.2018.

10. Pallesen S, Bjorvatn B, Nordhus IH et al. A new scale for measuring insomnia: the Bergen Insomnia Scale. Percept Mot Skills 2008; 107: 691-706. [PubMed][CrossRef]

11. Bjelland I, Dahl AA, Haug TT et al. The validity of the Hospital Anxiety and Depression Scale. An updated literature review. J Psychosom Res 2002; 52: 69-77. [PubMed][CrossRef]

12. Chung KF, Yeung WF, Ho FY et al. Cross-cultural and comparative epidemiology of insomnia: the Diagnostic and statistical manual (DSM), International classification of diseases (ICD) and International classification of sleep disorders (ICSD). Sleep Med 2015; 16: 477-82. [PubMed][CrossRef]

13. Hrubos-Strøm H, Randby A, Namtvedt SK et al. A Norwegian population-based study on the risk and prevalence of obstructive sleep apnea. The Akershus Sleep Apnea Project (ASAP). J Sleep Res 2011; 20: 162-70. [PubMed][CrossRef]

14. Bjorvatn B, Rajakulendren N, Lehmann S et al. Increased severity of obstructive sleep apnea is associated with less anxiety and depression. J Sleep Res 2017; 27: e 12647.

Publisert: 2. januar 2020. Tidsskr Nor Legeforen. DOI: 10.4045/tidsskr.19.0041

Mottatt 11.1.2019, første revisjon innsendt 17.6.2019, godkjent 23.10.2019.

(C) Tidsskrift for Den norske legeforening 2020. Lastet ned fra tidsskriftet.no 